\title{
TRAVEL TIMES FROM BLASTS IN SOUTHERN CALIFORNIA*
}

\author{
By B. GutenberG
}

\begin{abstract}
Seismograms recorded from a blast of about 70 tons of Du Pont "Nitramon" in tunnels at a quarry near Corona, southern California, are discussed. Arrival times of $P$ waves indicate a velocity of between 5.7 and $6.0 \mathrm{~km} / \mathrm{sec}$. in the upper $6 \mathrm{~km}$. of the region, and a velocity of about $61 / 2 \mathrm{~km} / \mathrm{sec}$. at a depth of $10 \mathrm{~km}$. The Mohorovičić discontinuity is at a depth of the order of $40 \mathrm{~km}$. The velocity below it is 8.1 to $8.2 \mathrm{~km} / \mathrm{sec}$. The amplitudes of $S$ waves are only slightly more than one-tenth of those in an earthquake having $P$ waves of equal amplitudes. The ratio of the velocity of $P$ to that of the first recognizable $S$ is found between 1.6 and 1.7. The first $S$ waves at distances up to about $140 \mathrm{~km}$. indicate a velocity of transverse waves of about $33 / 4 \mathrm{~km} / \mathrm{sec}$. at a depth of the order of $10 \mathrm{~km}$. A phase with an apparent velocity of about $31 / 2 \mathrm{~km} / \mathrm{sec}$. can be traced to more than $400 \mathrm{~km}$. It is followed by several slower phases. On the assumption that the amplitudes of $\mathrm{Pn}$ do not differ appreciably from those in an earthquake of the same magnitude, the blast would have had a magnitude of about 4 .
\end{abstract}

ON August 6, 3:30:00.0 P.M., P.S.T., one shot of about 70 metric tons of Du Pont "Nitramon," distributed in three tunnels and starting about 100 feet from the entrance, was fired at a quarry of the Minnesota Mining and Manufacturing Company near Corona, southern California (latitude $33^{\circ} 50$ '.81 N, longitude $117^{\circ} 30.36 \mathrm{~W}$ ) to break up about half a million cubic yards of dacite porphyry for commercial purposes. Careful preparations were made for the timing and recording of this blast. We had cordial coöperation from all concerned. Staff members of the Department of Terrestrial Magnetism of the Carnegie Institution of Washington, headed by Dr. M. Tuve, participated in the arrangements. The late Mr. W. J. Rooney arranged the firing of the blast to coincide with a radio time signal. A portable seismograph of the Seismological Laboratory recorded the explosion at a distance of about 300 meters from the shot point. Longitudinal waves were recorded at the eight permanent and four temporary stations of the Seismological Laboratory as well as at Boulder City, Pierce Ferry, and Overton, and at several portable stations installed by Dr. Tuve. For the latter, no readings are available at the time of writing. Seismograms recorded at the three stations of the Lake Mead Seismological Survey (United States Coast and Geodetic Survey) were kindly furnished by Mr. Frank Werner, and data for Lick Observatory by Dr. Perry Byerly.

Coördinates of the stations and data on the instruments are given in table 1 . Observed travel times of phases in the $\mathrm{P}$ group are summarized in table 2 . In figure 1 the times of the earlier $\mathrm{P}$ phases are plotted for distances up to 140 $\mathrm{km}$. after deducting $\Delta / 6$ to permit the use of a larger time scale. Times for $\mathrm{Pn}$

\footnotetext{
* Manuscript received for publication March 24, 1950.
} 
TABLE 1

Coördinates of Stattons and Instruments Used

(BZ = short-period Benioff vertical seismograph; $\mathrm{BH}=$ corresponding horizontal seismographs; WA = standard short-period Wood-Anderson torsion seismographs; $\mathrm{O}=$ other instruments.)

\begin{tabular}{|c|c|c|c|c|}
\hline Station & Lat. N & Long. W & Elev. & Instruments \\
\hline Pasadena..... & $\begin{array}{l}\text { deg. min. } \\
3408.9\end{array}$ & $\begin{array}{l}\text { deg. min. } \\
11810.3\end{array}$ & $\begin{array}{l}m . \\
295\end{array}$ & $\mathrm{BZ}, \mathrm{BH}, \mathrm{WA}, \mathrm{O}$ \\
\hline Mount Wilson. & 3413.5 & $118 \quad 03.4$ & 1742 & $\mathrm{BZ}, \mathrm{WA}$ \\
\hline Riverside..... & 3359.6 & 11722.5 & 250 & $\mathrm{BZ}, \mathrm{WA}$ \\
\hline Palomar....... & 3321.3 & 11651.6 & 1700 & $\mathrm{BZ}, \mathrm{BH}$ \\
\hline La Jolla. . . . . . & 3251.8 & 11715.2 & 8 & $\mathrm{BZ}, \mathrm{WA}$ \\
\hline Santa Barbara. & 3426.5 & 11942.9 & 100 & $\mathrm{BZ}, \mathrm{WA}$ \\
\hline Haiwee.... . . . & 3608.2 & 11757.9 & 1100 & $\mathrm{BZ}, \mathrm{WA}$ \\
\hline Tinemaha..... & 3705.7 & 11815.5 & 1180 & $\mathrm{BZ}, \mathrm{WA}$ \\
\hline Perris....... & 3346.8 & 11714.0 & 440 & $\mathrm{BZ}$ \\
\hline Pomona...... & 3405.9 & 11742.6 & 350 & $\mathrm{BZ}$ \\
\hline Crestline.... & 3414.6 & 11715.7 & 1400 & $\mathrm{BZ}$ \\
\hline El Cajon....... & 3247.6 & 11657.3 & 135 & $\mathrm{BH}$ \\
\hline Boulder City. . & $355851^{\prime \prime}$ & $1145002^{\prime \prime}$ & 776 & $\mathrm{BZ}, \mathrm{BH}$ \\
\hline Pierce Ferry... & $360714^{\prime \prime}$ & $1140016^{\prime \prime}$ & 417 & $\mathrm{BZ}, \mathrm{BH}$ \\
\hline Overton....... & $363153^{\prime \prime}$ & $1142635^{\prime \prime}$ & 395 & $\mathrm{O}$ \\
\hline
\end{tabular}

TABLE 2

Travel Times of Phases in the P Group of the Corona Blast Records, Based on Origin Time at 15:30:00.0 P.S.T.

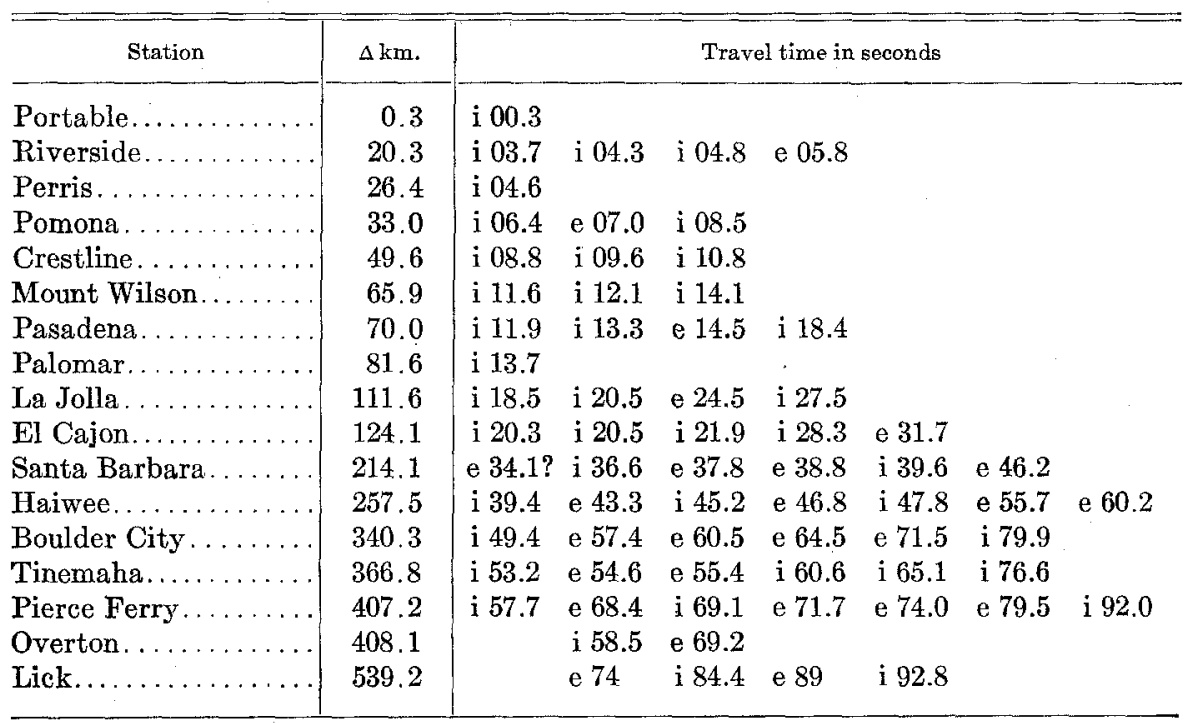


have been plotted elsewhere. ${ }^{1}$ Travel times from previous blasting in southern California reported by Wood and Richter (1933), ${ }^{2}$ as well as a few unpublished readings by Dr. C. F. Richter from a blast near Colton on November 3, 1949, have been added in figure 1 . The combined data include travel times along various azimuths. The agreement between them indicates that no considerable dipping of the layers is to be expected in the area involved.

The times of the first arrivals in figure 1 indicate that at a distance of 50 to $60 \mathrm{~km}$. the apparent velocity of the first $P$ waves increases. The first branch indicates a velocity of between about 5.6 and $6.0 \mathrm{~km} / \mathrm{sec}$. The value depends

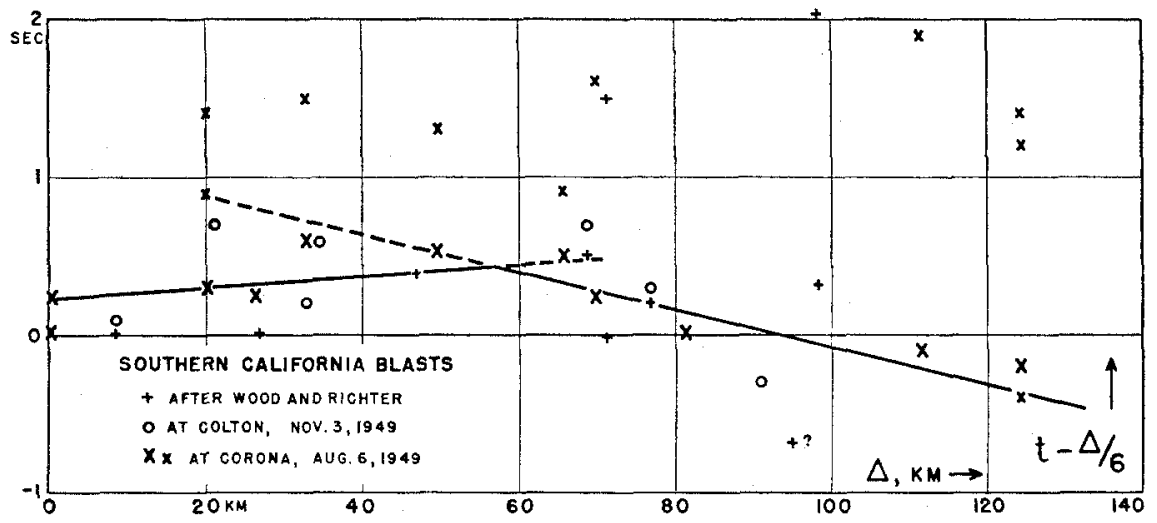

Fig. 1. Travel times of $\mathrm{P}$ waves minus $\Delta / 6$ from blasts in southern California $(\Delta=$ distance in $\mathrm{km}$.).

on the accurate time of the explosion and the effect of the sedimentary and other low-velocity layers near the surface at the source and the stations. The relatively long travel time of 0.3 second to the portable instrument at a distance of about 300 meters is probably mainly an effect of such low velocities, but a noticeable delay between the time signal at 15:30:00.0 and the actual explosion may also be involved. In the Corona blast the combined effect of both is an intercept time of about $1 / 4$ second for the travel-time curve of the first $P$ waves (first branch in fig. 1).

For a first calculation of the velocity as a function of depth the two lines indicated in figure 1 have been used. If $\Delta=$ distance in $\mathrm{km}$., they correspond to a travel time $t$ given by

$$
t=0.25+0.170 \Delta \quad \text { and } \quad t=1.1+0.155 \Delta
$$

respectively. These travel times would indicate that under the uppermost low-

${ }^{1}$ B. Gutenberg, "Revised Travel Times in Southern California," figure 3, Bull. Seism. Soc. Am. (in press).

${ }^{2}$ H. O. Wood and C. F. Richter, "A Second Study of Blasting Recorded in Southern California," Bull. Seism. Soc. Am., 23:95-110 (1933). 
velocity layers (mainly sediments) there is a layer with a velocity of about 5.9 $\mathrm{km} / \mathrm{sec}$. which extends to a depth of about $6 \mathrm{~km}$., where the velocity increases to about $6.45 \mathrm{~km} / \mathrm{sec}$. If it is assumed that the transition from the first to the second branch is gradual, the resulting velocity curve shows a corresponding gradual increase in velocity from about $53 / 4 \mathrm{~km} / \mathrm{sec}$. at a depth of $1 \mathrm{~km}$. to $6 \mathrm{~km} / \mathrm{sec}$. at a depth of about $4 \mathrm{~km}$., $6.4 \mathrm{~km} / \mathrm{sec}$. at about $8 \mathrm{~km}$. depth, and to about $6.5 \mathrm{~km} / \mathrm{sec}$. at a depth of $10 \mathrm{~km}$.

Unfortunately, there are no reliable data for distances between about 124 and $257 \mathrm{~km}$. The beginning of the record at Santa Barbara $(\Delta=214.1 \mathrm{~km}$.) is not clear. A branch of the travel-time curve indicating velocities of the order

TABLE 3

Orserved Travel Times $t$ in Seconds of Pn, Assuming Origin Time at 15:30:00.0 P.S.T.

\begin{tabular}{|c|c|c|c|c|}
\hline Station & $\Delta \mathrm{km}$. & $t$ & $\Delta / 8.2$ & $t-\Delta / 8.2$ \\
\hline Santa Barbara. & 214.1 & $34.1 ?$ & 26.1 & $8.0 ?$ \\
\hline Haiwee... . . . . & 257.5 & 39.4 & 31.4 & 8.0 \\
\hline Boulder City. & 340.3 & $49.4 \pm$ & 41.5 & $7.9 \pm$ \\
\hline Tinemaha... & 366.8 & $53.2 \pm$ & 44.7 & $8.5 \pm$ \\
\hline Pierce Ferry....... & 407.2 & 57.7 & 49.7 & 8.0 \\
\hline
\end{tabular}

of $7 \mathrm{~km} / \mathrm{sec}$. has been established in other areas. Seismograms from distances between about 150 and $250 \mathrm{~km}$. are needed for finding of such an additional branch. $^{3}$

Table 3 gives readings for $\mathrm{Pn}$. The beginning is especially clear at Haiwee and at Pierce Ferry. Seismograms of both stations are reproduced in the lower part of figure 2. Table 3 indicates that the apparent velocity of Pn is close to $8.2 \mathrm{~km} / \mathrm{sec}$. and the intercept time close to 8 seconds. Pn at Tinemaha shows the delay which is usual for Pn waves which have traveled along northern Owens Valley.

The depth $d$ of the Mohorovičić discontinuity cannot be calculated accurately since the velocity in the depth interval between about $10 \mathrm{~km}$. and the discontinuity is not well known. The order of magnitude of $d$ is $40 \mathrm{~km}$. The

${ }^{3}$ Dr. Tuve and Dr. Tatel have reported their results, at a meeting of the American Geophysical Union held on May 2, 1950 (see abstract in Trans. Am. Geophys. Union, 31:324). They find that "the apparent velocities of the $P$ waves increase from a surface velocity of $5.7 \mathrm{~km} / \mathrm{sec}$. to a velocity of $6.8 \mathrm{~km} / \mathrm{sec}$. at a depth of about $10 \mathrm{~km}$." Their times of first arrivals on two records from distances of about 8 and $28 \mathrm{~km}$., respectively, fall close to the first branch of the travel-time curve in figure 1. Records at six stations with distances between 70 and $148 \mathrm{~km}$. establish a branch with an apparent velocity of 6.8 to $6.9 \mathrm{~km} / \mathrm{sec}$. which also fits the points below the second branch in figure 1. Later readings for some of these stations are close to the solid line (second branch) at distances greater than $70 \mathrm{~km}$. in figure 1. One observation at a distance of $325 \mathrm{~km}$. agrees with the travel times for Pn in table 3 and gives $t-\Delta / 8.2=7.9$ sec. [This note was added in May, 1950.] 


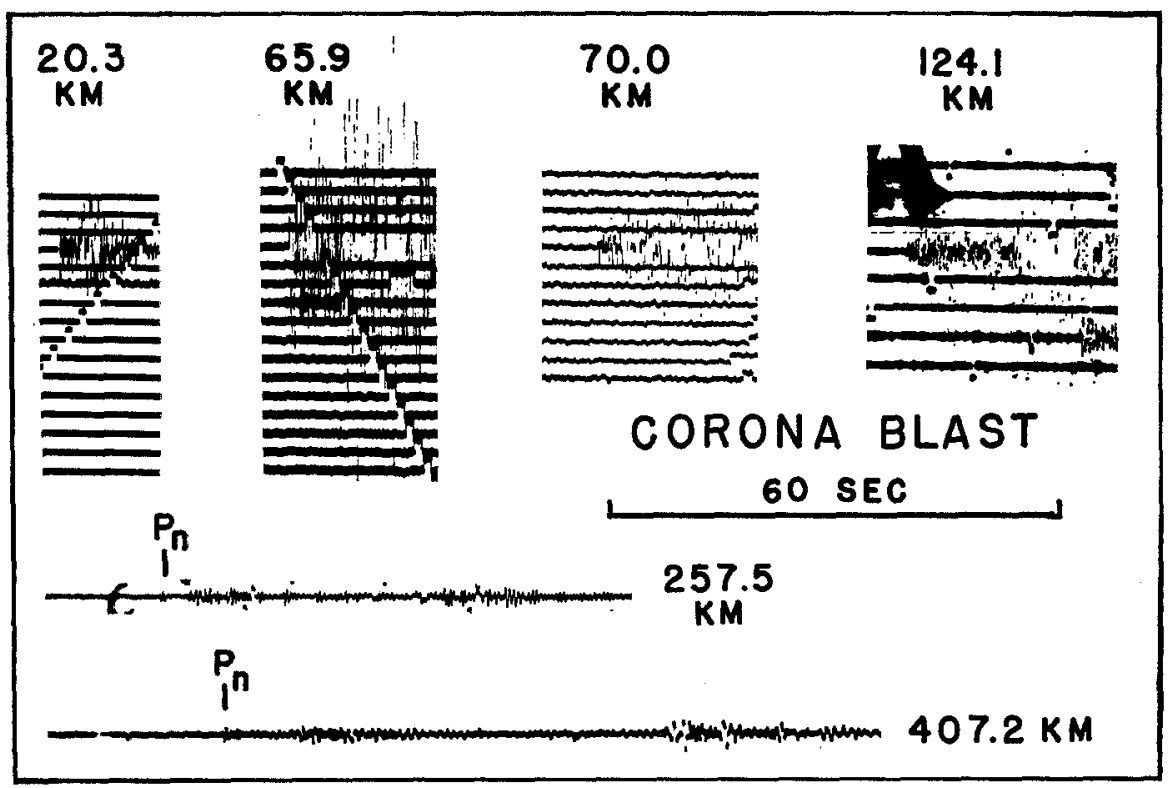

Fig. 2. Corona blast records. Top line, left to right: Riverside, torsion seismograph EW; Mount Wilson, short-period Benioff vertical; Pasadena, short-period Benioff vertical; El Cajon, short-period Benioff EW (recorded on film). Below: Haiwee and Pierce Ferry, short-period Benioff verticals (Pierce Ferry recorded on film).
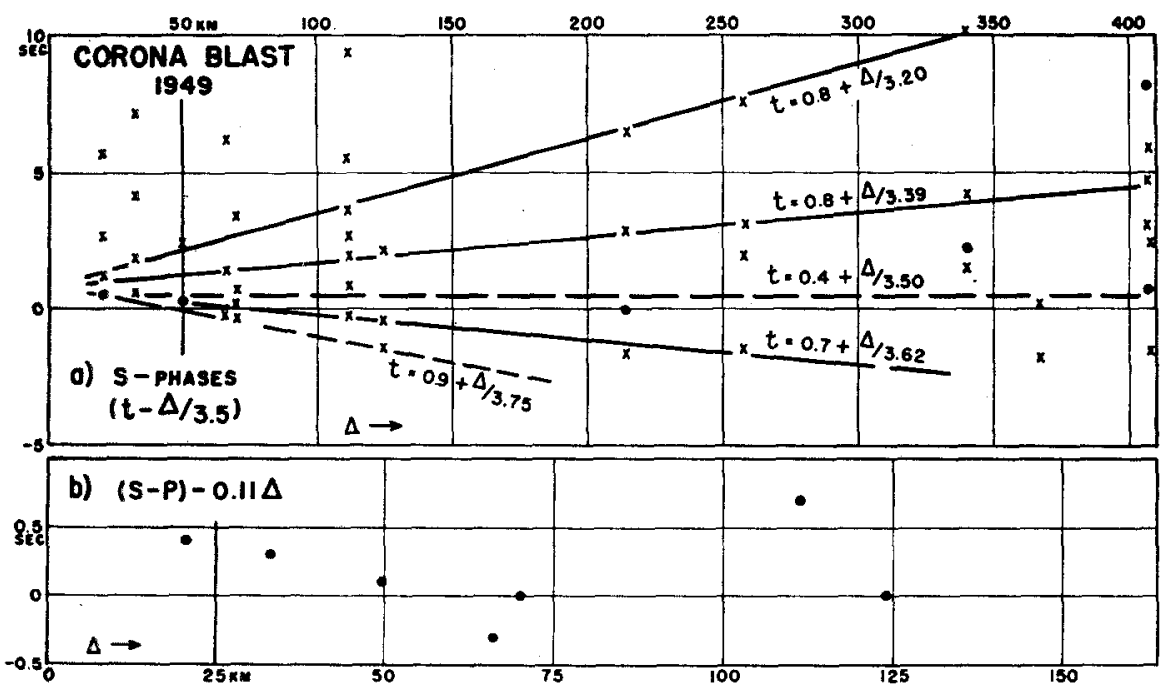

Fig. 3. (a) Travel times of $\mathrm{S}$ phases minus $\Delta / 3.5$ and $(b) \mathrm{S}-\mathrm{P}$ minus $0.11 \Delta$ from Corona blast, August $6,1949(\Delta=$ distance in $\mathrm{km}$.). 
actual velocity $V$ of $\mathrm{Pn}$ below this depth is about $0.05 \mathrm{~km} / \mathrm{sec}$. smaller than the apparent velocity $\bar{V}$ since

$$
\bar{V}-V=\bar{V} d / R
$$

where $R=$ radius of the earth.

Travel times of phases in the $\mathrm{S}$ group are given in table 4 . It is often not possible to determine the exact beginning of the $\mathrm{S}$ group. Travel times of $\mathrm{S}$ phases have been plotted in figure $3, a$, after subtracting $\Delta / 3.5$, and differences $\mathrm{S}-\mathrm{P}$ after deduction of $0.11 \Delta$ in figure $3, b$. They do not indicate the break in two branches near $\Delta=50$ to $60 \mathrm{~km}$. which has been found for $\mathrm{P}$ (fig. 1).

TABLE 4

Trayel Times of Phases in the S Group of the Corona Blast Records

\begin{tabular}{|c|c|c|c|c|c|c|c|c|}
\hline Station & $\Delta \mathrm{km}$ & \multicolumn{5}{|c|}{ Time in seconds } & $\mathbf{S}-\mathbf{P}$ & $\mathrm{S} / \mathrm{P}$ \\
\hline Riverside. & 20.3 & i 06.3 & e 07 & e $081 / 2$ & e $11 \frac{1}{2} / 2$ & & 2.6 & 1.70 \\
\hline Pomona.. & 33.0 & e 10.0 & e 11.2 & e 13.6 & e 16.6 & & 3.9 & 1.64 \\
\hline Crestline. ..... & 49.6 & i 14.4 & i 16.6 & & & & 5.6 & 1.64 \\
\hline Mount Wilson. . & 65.9 & e 18.5 & i 20.2 & i 25 & e 34 & i $411 / 2$ & 6.9 & 1.59 \\
\hline Pasadena. ..... & 70.0 & i 19.6 & i 20.2 & i 20.7 & e 23.4 & & 7.7 & 1.65 \\
\hline La Jollạ. . & 111.6 & e 31.5 & e 32.7 & e 33.8 & i 35.5 & e $371 / 2$ e 41.3 & 13.0 & 1.70 \\
\hline El Cajon....... & 124.1 & e 34.0 & e 35.0 & i 37.6 & & & 13.7 & 1.68 \\
\hline Santa Barbara. & 214.1 & e 59.5 & i 61.3 & e 64 & e 67.7 & & & \\
\hline Haiwee........ & 257.5 & e 72.1 & e 75.5 & e 76.7 & $\mathrm{e} 77.7$ & e 81.2 & & \\
\hline Boulder City... & 340.3 & i 98.7 & i 99.4 & e 101.4 & e 107.5 & e 115.4 e 120.5 & & \\
\hline Tinemaha..... & 366.8 & e 103 & e 105 & & & & & \\
\hline Pierce Ferry... & 407.2 & i 117 & i 119.3 & e 121 & i $1241 / 2$ & i $1271 / 2$ i $1341 / 2$ & & \\
\hline Overton...... & 408.1 & e 115 & e 119 & e $1221 / 2$ & i 134 & e 148 & & \\
\hline
\end{tabular}

Since $\mathrm{S}$ is probably read too late on many records, the ratio $\mathrm{S} / \mathrm{P}$ of between 1.6 and 1.7 (last column of table 4 ) is smaller than the corresponding value of 1.73 found from earthquake records.

If the velocities $V$ and $v$ are constant, in records from a surface source

$$
\mathrm{S}-\mathrm{P}=C \Delta \quad \text { where } \quad C=\frac{1}{v}-\frac{1}{V}=\frac{1}{V}\left(\frac{V}{v}-1\right)
$$

If Poisson's ratio is $0.25, C=0.732(1 / V)$. From figure $3, b$ it follows that $C$ is about 0.112 . Since there is a difference in the paths of earthquake waves and blast waves arriving at the same distance, and since $C$ is approximately proportional to $1 / V$, it cannot be expected that the value of $C$ in a blast is equal to that in earthquakes, which was found to be about 0.115 at distances up to about $140 \mathrm{~km}$. in southern California earthquakes. In seismograms of the Corona blast recorded at distances greater than about $150 \mathrm{~km}$. the earlier $\mathrm{S}$ phases have apparently not been found. Especially, there is no record showing an identifiable Sn phase. 


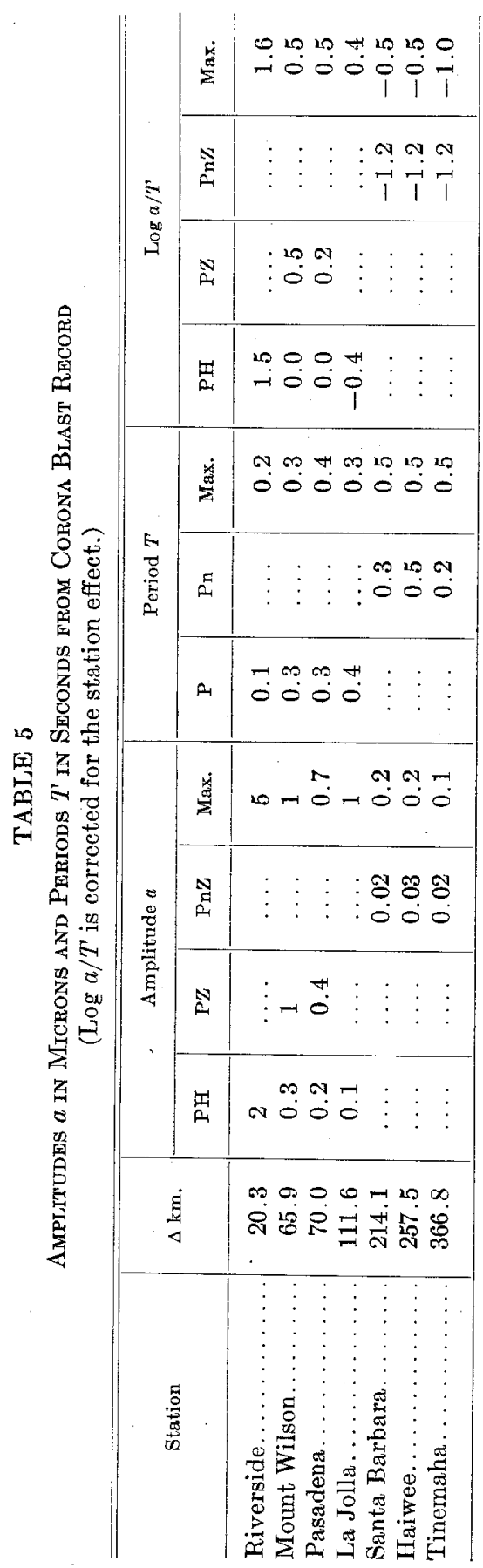


There are phases in several records which create the impression of reflections from discontinuities (such as P33P, etc.), ${ }^{4}$ but the data are too scanty for an investigation.

Amplitudes and periods of the main phases have been measured. Essential data are given in table 5 . The results for the $P$ waves at the first four stations and for the maximum cannot be easily correlated with corresponding data from earthquake records since the $\mathrm{P}$ waves observed at distances less than 150 $\mathrm{km}$. have entirely different paths in blasts and in earthquakes and the maxima are relatively much smaller in blast records than in earthquake records. The amplitudes of $\mathrm{Pn}$ should be least affected by the difference in the focal depth and the type of movement near the source in the two cases. However, it must be considered that the energy going into a refracted wave nearly grazing a discontinuity depends on the distance of the source from this discontinuity, a quantity which differs appreciably in blasts and in earthquakes. From comparison with earthquake data it would follow that Pn in the Corona blast had about the same amplitudes as $\mathrm{Pn}$ in an earthquake of magnitude 4. In seismograms from near-by earthquakes the maxima are usually in the S group. In the Corona blast records the maxima decrease with distance very nearly as in an earthquake of magnitude 3.1. This indicates that the energy which these phases in the $\mathrm{S}$ group have received in the blast is only of the order of magnitude of one per cent of the energy which they would have received in an earthquake with the same energy in $\mathrm{Pn}$.

California Institute of Technology

Pasadena, California

(Division of Geological Sciences, contribution no. 536)

'B. Gutenberg, "Reflected and Minor Phases in Records of Near-by Earthquakes in Southern California," Bull. Seism. Soc. Am., 34:137-160 (1944). 